Journal of the Electrochemical Society, Vol. 153, No. 12, 2006, pp. B533-B541.

ISSN: (print 0013-4651)(online 1945-7111)

DOI: $10.1149 / 1.2358843$

http://scitation.aip.org/JES

http://scitation.aip.org/getpdf/servlet/GetPDFServlet?filetype=pdf\&id=JESOAN00015300001200B533000001\&idty pe $=$ cvips\&prog $=$ normal

(C) The Electrochemical Society, Inc. 2006. All rights reserved. Except as provided under U.S. copyright law, this work may not be reproduced, resold, distributed, or modified without the express permission of The Electrochemical Society (ECS). The archival version of this work was published in Journal of the Electrochemical Society, Vol. 153, No. 12, 2006, pp. B533-B541.

\title{
Aluminum Alloy Corrosion Inhibition by Vanadates
}

\author{
M. Iannuzzi, ${ }^{a}$ T. Young, ${ }^{b}$ and G. S. Frankel ${ }^{a}$ \\ ${ }^{a}$ Fontana Corrosion Center, and ${ }^{b}$ Department of Chemistry, The Ohio State University, Columbus, Ohio
}

\begin{abstract}
The inhibition of $\mathrm{Al}$ alloy corrosion by vanadates was studied in this work. Vanadium speciation is very complicated and vital to the inhibition efficacy. Critical conditions for decavanadate polymerization from clear metavanadate solutions were investigated. Decavanadate only formed when metavanadate was added to solutions of $\mathrm{pH} 3$ or less. It was not possible to change the $\mathrm{pH}$ of a metavanadate solution without forming decavanadates, creating an orange-colored solution. According to ${ }^{51} \mathrm{~V}$ nuclear magnetic resonance, monovanadates were present only in clear metavanadate solutions; orange solutions always contained decavanadates and never contained monovanadates. Orange decavanadate solutions containing $0.5 \mathrm{M} \mathrm{NaCl}$ at $\mathrm{pH} 8.71$ exhibited no significant inhibition of the oxygen reduction reaction and increasing decavanadate concentration was detrimental. In contrast, clear metavanadate solutions containing monovanadate exhibited strong inhibition of the oxygen reduction reaction, to a level similar to chromate. At a fixed $\mathrm{pH}$, increased $\mathrm{NaVO}_{3}$ concentration in clear metavanadate solutions increased inhibition efficiency.
\end{abstract}

High-strength aluminum alloys are used widely in structural aircraft applications because of the combination of good mechanical properties and light weight. ${ }^{1,2}$ However, aluminum alloys are prone to localized corrosion if exposed to aggressive environments containing chloride ions. ${ }^{3-}$ ${ }^{6}$ Current protection schemes are based on the chemistry of chromate oxoanions. Chromates and dichromates in aqueous solutions, as conversion coatings or as pigment in primers, impart excellent corrosion protection to most aluminum alloys. ${ }^{7-14}$ The mechanism thought to be responsible for such potent inhibition involves the formation of a $\mathrm{Cr}^{3+}$ monolayer at the surface which impedes both oxygen and further $\mathrm{Cr}^{6+}$ electrochemical reduction. ${ }^{14-20}$ After the formation of this $\mathrm{Cr}^{3+}$ monolayer, a surface film with a mixed $3+/ 6+$ oxidation state develops. ${ }^{18}$ The mixed oxidation state is responsible for the reported self-healing capabilities of chromate-based systems. ${ }^{7,9,13,18,21-24}$ Labile $\mathrm{Cr}^{6+}$ can be released from the coating and migrate to a damaged region where electrochemical reduction to $\mathrm{Cr}^{3+}$ can occur, protecting the surface from further corrosion..$^{7,8,12,18,21,23,24}$ Despite their excellent performance, several regulations prohibit the use of $\mathrm{Cr}^{6+}$ technologies due to their high toxicity and carcinogenic effects. ${ }^{25}$ The pressure imposed by these regulations has been a significant driving force promoting the development of chromatefree alternatives. As summarized by Kendig and Buchheit, compounds derived from almost 40 elements of the periodic table and combinations of them have been investigated. ${ }^{9,14}$ However, no suitable alternatives for high-strength $\mathrm{Al}$ alloys have been reported to date.

Vanadium-based oxyanions, also referred to as vanadates, have been investigated as corrosion inhibitors for Al alloys. However, they have not gained much attention probably due to the relatively large solubility of vanadium oxides in aqueous solutions., ${ }^{9,14,26,27}$ Smith et al. explored the release kinetics and protection performance of vanadate-based pigments in epoxy- 
coated AA2014-T6 panels. The authors concluded that vanadates are effective pigments for protecting $\mathrm{Al}$ alloys. ${ }^{28} \mathrm{~A}$ later investigation by Cook et al. screened and compared several candidate inhibitors including vanadates, molybdates, and ions of rare earth elements like Ce, Y, and $\mathrm{La}^{29}$ The authors concluded that in aqueous solutions at neutral to basic $\mathrm{pHs}$, vanadates gave the best performance, reaching, in some cases, chromate-like levels. Interestingly, at lower pHs no inhibitor imparted good protection; however, vanadates were among the best performing compounds. Buchheit et al. developed a surface conversion process for aluminum alloys based on acidic vanadium formulations, which imparted protection to AA2024-T3 coated panels to some extent. ${ }^{26}$ In addition, the authors analyzed the behavior of aqueous solutions containing vanadium oxoanions and concluded that metavanadates, i.e., vanadate oligomers including $\mathrm{V}_{1}$, $\mathrm{V}_{2}, \mathrm{~V}_{4}$, and $\mathrm{V}_{5}$ coordination, are not potent inhibitors of the oxygen reduction reaction (ORR) but significantly lower the anodic dissolution kinetics. Buchheit et al. also explored the use of vanadates as a counterion in hydrotalcite coatings. The authors reported that migration of vanadates from the coating can impart active corrosion protection. ${ }^{30}$ Recently, Chambers et al. studied the synergism of several binary and ternary mixtures including vanadates, phosphates, molybdates, and several rare earths. The authors concluded that the maximum synergistic effect occurred for vanadate-phosphate solutions in a 50:50 ratio. ${ }^{31}$ However, all of these studies of inhibition by vanadates lacked information regarding vanadate speciation in the test solutions, and interpretations were based on the analysis of speciation diagrams, which do not consider metastable phases.

The coordination chemistry of vanadium oxoanions in aqueous solutions is rather complex. It involves several protonation/deprotonation reactions, as well as polymerization to form oligomers of varied molecular weight, depending upon $\mathrm{pH}$ and concentration. ${ }^{32-36}$ In general, all the polymerized species are referred to as isopolyanions or isopolymetallates. ${ }^{34,36-38}$

In part, as a consequence of the role played by vanadates in modifying several biochemical processes, vanadate speciation has been the subject of several review studies that characterized the system in detail. ${ }^{39-47}$ Initially, techniques such as ultraviolet/visible spectroscopy, $\mathrm{pH}$ measurements, and electrochemical studies were employed to determine the stoichiometry of the equilibria of the different vanadate species. ${ }^{48,49}$ However, the information extracted from those techniques is rather limited and possesses virtually no direct evidence of the coordination structure of the different isopolyanions and in some cases, was proven to be incorrect. ${ }^{41,42}$ It was not until the maturing of nuclear magnetic resonance (NMR) spectroscopy that the exact structure and concentration of the different V42 oligomers present in aqueous solutions were understood. Nevertheless, there is still some debate regarding existence and coordination of some species such as $\mathrm{V}_{3} \mathrm{O}_{9}^{3-} \cdot{ }^{42-44}$

Modern high-field NMR gives high-quality structural data and quantitative information regarding speciation and concentration of a large variety of compounds in aqueous and nonaqueous solvents. ${ }^{50}$ The only limitation of NMR is the inability of detecting minor components with overlapping or coincident chemical shifts. ${ }^{50}$ According to ${ }^{51} \mathrm{~V}$ and ${ }^{17} \mathrm{O} \mathrm{NMR}$ spectroscopy, the observed oligomers in the range of $\mathrm{pH}$ 7-9 and at varied vanadate concentrations are the monovanadates $\left(\mathrm{V}_{1}\right)$, divanadates $\left(\mathrm{V}_{2}\right)$, cyclic tetravanadates $\left(\mathrm{V}_{4}\right)$, and cyclic pentavanadates $\left(\mathrm{V}_{5}\right){ }^{42-44}$ In contrast, decavanadates are stable in the $\mathrm{pH}$ range from 2 to 6 but can form in solutions of higher $\mathrm{pH}$ due to local acidification of the solution. . $^{32,36,39,41,44}$ Polymerization to $\mathrm{V}_{10}$ is rapid and the mechanism of formation is not well understood. 


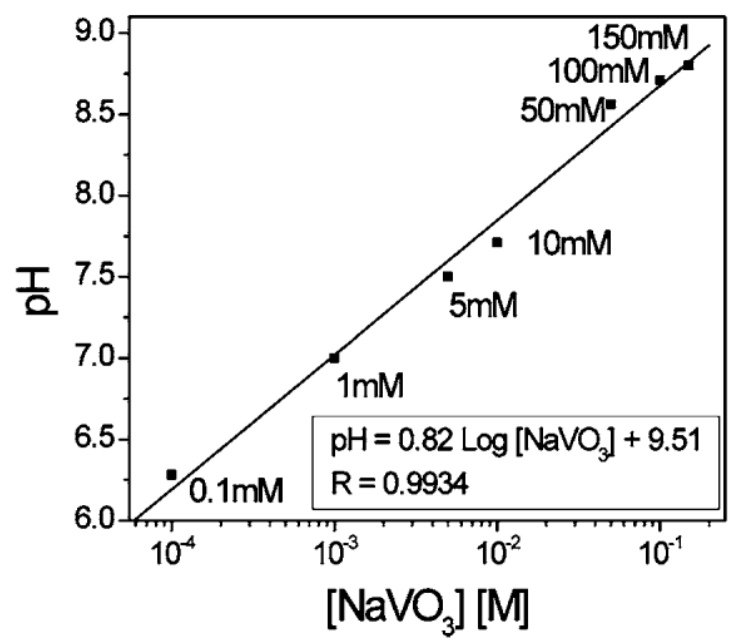

Figure 1. $\mathrm{pH}$ of clear, as-dissolved solutions as a function of $\mathrm{NaVO}_{3}$ concentration.

Depolymerization of $\mathrm{V}_{10}$, on the other hand, is very slow. ${ }^{39}$ Heating can be used to precipitate decavanadate crystals out of aqueous solutions. ${ }^{51}$

The results of prior studies on corrosion inhibition by vanadates are clouded by a lack of understanding of speciation, the complexity of the hydrolysis of vanadates in aqueous solutions, and the existence of metastable equilibria. The main objective of this work is to understand which vanadate oligomer imparts the best corrosion protection for AA2024-T3. Vanadate speciation as a function of $\mathrm{pH}$ and concentration is investigated by ${ }^{51} \mathrm{~V}$ NMR. The influence of decavanadate formation, solution aging, and bulk $\mathrm{pH}$ on corrosion inhibition of AA2024-T3 is also addressed.

\section{Experimental}

Materials and sample preparation.- Commercially available sodium vanadium oxide, $98 \% \mathrm{NaVO}_{3}$, and reagent-grade sodium chloride from Sigma-Aldrich were used. All solutions were prepared with $18.2 \mathrm{M} \Omega \mathrm{cm}$ deionized water.

To reduce the possibility of composition or heat-treatment artifacts, samples were cut from two different AA2024-T3 panels (nominal composition 3.8-4.9\% Cu, 1.2-1.8\% Mg, 0.3$0.9 \% \mathrm{Mn}, 0.5 \% \mathrm{Fe}, 0.5 \% \mathrm{Si}, 0.25 \% \mathrm{Zn}, 0.1 \% \mathrm{Cr}, 0.05 \% \mathrm{Ti}$, balance $\mathrm{Al}$ ) that were 1 and $5 \mathrm{~mm}$ thick, respectively. The samples were mounted in epoxy resin; ground through 1200 grit $\mathrm{SiC}$ papers (Buehler), and polished with 3 and $1 \mu \mathrm{m}$ diamond paste (Buehler). Ethyl alcohol $(<0.2 \%$ water) was used as a lubricant during all the surface preparation stages to minimize corrosion damage during grinding and polishing.

Determination of the minimum $\mathrm{pH}$ that triggers orange $V_{10}$ polymerization. - Asprepared, $\mathrm{NaVO}_{3}$ solutions remain colorless with a $\mathrm{pH}$ that linearly increases with total vanadium concentration (Fig. 1). Acidification with concentrated $\mathrm{HCl}$ to adjust bulk $\mathrm{pH}$ produces a change in color to orange indicating the formation of decavanadates. The determination of the minimum $\mathrm{pH}$ that causes $\mathrm{V}_{10}$ formation was investigated. At the same time it was possible to determine whether the bulk $\mathrm{pH}$ can be adjusted without introducing color change. Aliquots of colorless 150 $\mathrm{mM} \mathrm{NaVO}+0.5 \mathrm{M} \mathrm{NaCl}$ solutions were added to beakers containing exclusively $0.5 \mathrm{M} \mathrm{NaCl}$ 
solutions with initial $\mathrm{pH}\left(\mathrm{pH}_{0}\right)$ varying from 1 to 12 . The $\mathrm{NaCl}$ solutions were not buffered to avoid any possible complexation between vanadium and the buffer media. Therefore, $\mathrm{pH}_{0}$ was adjusted and measured immediately before mixing. Final $\mathrm{NaVO}_{3}$ concentrations of 100 , 50 , or 5 $\mathrm{mM}$ were obtained by varying the injected volume. The final $\mathrm{pH}$ after mixing, $\mathrm{pH}_{\mathrm{f}}$, was monitored and determined as a function of $\mathrm{pH}_{0}$.

NMR spectroscopy. - Procedures for ${ }^{51} \mathrm{~V}$ NMR described in the literature were followed. ${ }^{39,42-47}$ High-resolution ${ }^{51} \mathrm{~V}(105.2 \mathrm{MHz})$ spectra were obtained at room temperature utilizing a Bruker DPX $400 \mathrm{MHz}$ superconducting magnet. A broadband direct detection $5 \mathrm{~mm}$ probe with a corresponding $5.9 \mathrm{~ms} 90^{\circ}$ pulse duration was used. The $\mathrm{V}$ chemical shifts were referenced to an external standard $20 \% \mathrm{v} / \mathrm{v} \mathrm{VOCl}_{3}$ in $\mathrm{C}_{6} \mathrm{D}_{6}\left(\delta^{51} V=0 \mathrm{ppm}\right)$. All spectra were acquired with an accumulation of 1024 transients using a spectral window of 75,158 Hz, an acquisition time of $0.03 \mathrm{~s}$, and a relaxation delay of $0.20 \mathrm{~s}$. The following processing parameters were applied to each spectrum prior to integration: $30 \mathrm{~Hz}$ line broadening, zero filling, and baseline corrections.

Speciation of clear metavanadate solutions and orange solutions containing decavanadate at varied concentrations was compared at the same high $\mathrm{pH}$. Decavanadate solutions were prepared by acidifying clear metavanadate solutions to $\mathrm{pH} 4$ to obtain an orange solution and readjusting the electrolyte to $\mathrm{pH} 8.71$ using $\mathrm{NaOH}$. The resulting solution remained colored at the high $\mathrm{pH}$. Metavanadate solutions were also directly adjusted to higher $\mathrm{pHs}$, and these solutions remained clear. The effects of $\mathrm{pH}$ on speciation and corrosion performance of clear metavanadate solutions were also analyzed by increasing the $\mathrm{pH}$ of $10 \mathrm{mM} \mathrm{NaVO}$ solutions with $\mathrm{pH}$ 7.8-10.

Electrochemical tests. - All electrochemical tests were carried out using either a Gamry PC3/300 or a VoltaLab PGP-201 potentiostat in a three-electrode array. A platinum mesh counter electrode and a standard calomel reference electrode (SCE) were used in all experiments. A Luggin capillary filled with an agar-agar gel made with $0.5 \mathrm{M} \mathrm{NaCl}$ was used in all tests. Samples were cleaned and degreased with ethyl alcohol before testing. Each experiment was repeated at least in triplicate. Cathodic polarization experiments were carried out in solutions that were bubbled with air for $1 \mathrm{~h}$ prior to the experiment and stirred during the experiment to generate a more reproducible limiting current for the ORR. The potential sweep started $10 \mathrm{mV}$ above the open circuit potential (OCP) and was stopped when the current density reached -2 $\mathrm{mA} / \mathrm{cm}^{2}$. A scan rate of $1 \mathrm{mV} / \mathrm{s}$ was used and the total exposed area was approximately $1 \mathrm{~cm}^{2}$. Corrosion rate at OCP was assessed from the polarization resistance $\left(R_{P}\right)$ determined using the linear polarization technique (LPT). The potential was scanned at $5 \mathrm{mV} / \mathrm{s}$ over a range $\pm 15 \mathrm{mV}$ relative to the OCP. LPT measurements were repeated each $30 \mathrm{~min}$ for $24 \mathrm{~h}$.

Long-term OCP exposure.- Samples were immersed in chloride solution containing decavanadate or metavanadate solution for 14 days. The solutions were renewed every $24 \mathrm{~h}$ to reduce the effects of changes in $\mathrm{pH}$ or speciation.

\section{Results and Discussion}

Determination of the minimum $\mathrm{pH}$ that triggers $V_{10}$ formation. - The objective of these experiments was to determine the critical conditions (i.e., initial $\mathrm{pH}$ and final vanadate 
concentration) that cause decavanadate formation, as evidenced by a change in color from clear to orange. The injection of the concentrated clear $150 \mathrm{mM} \mathrm{NaVO}_{3}$ solution was made slowly and recorded with a digital camera. Figure 2 shows the $\mathrm{pH}_{f}$ as a function of $\mathrm{pH}_{0}$. The color change associated with $\mathrm{V}_{10}$ formation was only triggered for $\mathrm{pH}_{0} \leq 3$, independent of final vanadate concentration. Interestingly, for $100 \mathrm{mM}$ and $50 \mathrm{mM}$ final vanadate concentrations, $\mathrm{pH}_{f}$ was equal to 8.4 independent of $\mathrm{pH}_{0}$ for $3 \leq \mathrm{pH}_{0}<12$. For $5 \mathrm{mM}$ total vanadate, $\mathrm{pH}_{f}$ was equal to 7.6 independent of $\mathrm{pH}_{0}$ for $4<\mathrm{pH}_{0}<12$. In other words, to create vanadate solutions of concentration $5 \mathrm{mM}$ or higher with $\mathrm{pH}$ less than 7.5, the vanadates must be mixed with solutions having $\mathrm{pH}$ less than 3-4. Since this $\mathrm{pH}$ range is above the $\mathrm{pH}$ for color change, a direct implication of these findings is the practical impossibility of adjusting the $\mathrm{pH}$ of clear $\mathrm{NaVO}_{3}$ solutions, without producing a change in color and speciation. Therefore, previous studies that

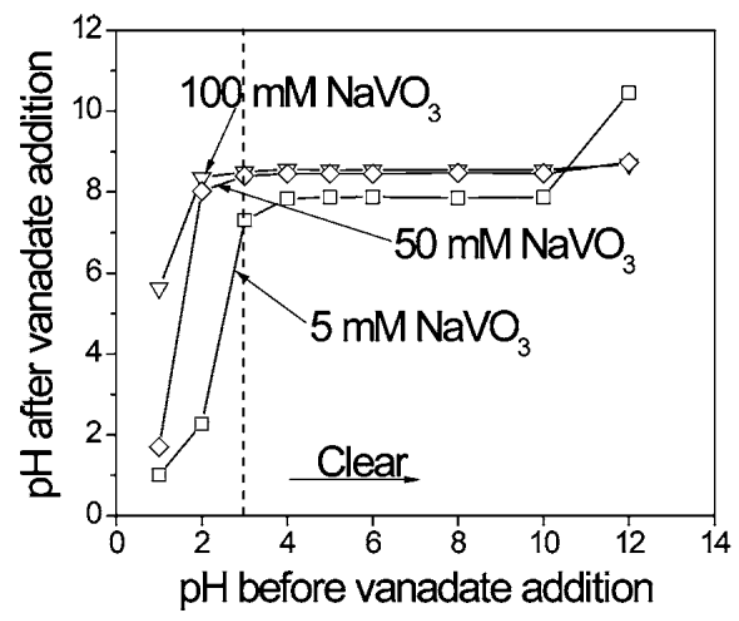

Figure 2. Final $\mathrm{pH}$ of solutions formed by mixing metavanadate with solutions of varying initial $\mathrm{pH}$. The concentration refers to the final vanadate concentration after mixing.

investigated inhibition by vanadates at $\mathrm{pH} 7$ actually used solutions containing decavanadate. ${ }^{26,29,30}$ Exact speciation of these solutions are addressed below. Once formed, however, orange decavanadate solutions can be adjusted to high $\mathrm{pH}$ without completely depolymerizing the $\mathrm{V}_{10}$ formed during acidification. Therefore, it was possible to analyze and compare clear metavanadate and orange decavanadate solutions at a common $\mathrm{pH}$ only at high $\mathrm{pH}$. Here solutions were adjusted to $\mathrm{pH} \mathrm{8.71,} \mathrm{which} \mathrm{corresponds} \mathrm{to} \mathrm{the} \mathrm{as-dissolved} \mathrm{pH}$ of 100 $\mathrm{mM} \mathrm{NaVO}_{3}$.

The fact that a local environment with a $\mathrm{pH} \leq 3$ triggers formation of decavanadates not only has direct implications in sample preparation procedures, but it might also impact coating schemes based on vanadates. The case of an epoxy coating containing a metavanadate pigment can be used as a simple example. If a scratch through the coating is exposed to an aggressive electrolyte, release of a vanadate species from the coating to the damaged area will occur. If the $\mathrm{pH}$ of the electrolyte is lower than 3, released metavanadates will polymerize to form decavanadates. In such a case, decavanadates will have to protect the exposed bare metal from further corrosion. On the other hand, if the $\mathrm{pH}$ of the aggressive electrolyte is greater than 4, metavanadates will be the species released and present in solution. 
Nuclear magnetic resonance spectroscopy (NMR). - ${ }^{51} \mathrm{~V}$ NMR was used to determine quantitatively the speciation of vanadate solutions. Decavanadates were prepared by first acidifying clear metavanadate solutions to $\mathrm{pH} 4$ and then readjusting to $\mathrm{pH} 8.71$. Since decavanadate solutions are not thermodynamically stable in these conditions, solutions were prepared immediately before NMR analysis.

Typical ${ }^{51} \mathrm{~V}$ NMR spectra for a $100 \mathrm{mM}$ decavanadate solution and a $100 \mathrm{mM}$ metavanadate solution adjusted to $\mathrm{pH} 8.71$ are shown in Fig. 3a and b. The peaks are labeled based on assignments reported in the literature. ${ }^{32,34,39,41-47}$ NMR peaks are proportional to the species concentration. ${ }^{50}$ Summations of the peak areas of spectra such as those in Fig. $3 \mathrm{a}$ and $\mathrm{b}$ from both decavanadate and metavanadate solutions of varying concentration are given in Fig. $3 \mathrm{c}$ and $\mathrm{d}$, respectively. In both cases, the sum of $n$ times the area under the peaks, where $n=1,2,4$, 5 , or 10 , linearly scaled with total vanadium concentration, thereby proving the validity of the peak assignment and providing a calibration of the method.

Figure 4 shows changes in speciation associated with $\mathrm{pH}$ adjustment. A typical ${ }^{51} \mathrm{~V}$ NMR spectrum of a $100 \mathrm{mM}$ clear metavanadate solution at $\mathrm{pH} 8.71$ is shown in Fig. 4a. The oligomers present in such conditions are the monovanadate $\left(\mathrm{V}_{1}\right)$, the divanadate $\left(\mathrm{V}_{2}\right)$, the tetravanadate $\left(\mathrm{V}_{4}\right)$, and the pentavanadate $\left(\mathrm{V}_{5}\right)$ as has been reported previously. ${ }^{32-34,41-43,50}$ At low concentrations (1-5 $\mathrm{mM} \mathrm{NaVO3)} \mathrm{V} 1$ is the predominant species, whereas at higher concentrations, such as the case of Fig. 4a, the oligomers of higher molecular weight become predominant. When the clear metavanadate solutions are acidified to $\mathrm{pH} 4$, all the metavanadates polymerize to form an orange decavanadate solution exclusively containing, within the detection limit of the instrument, signal from $\mathrm{V}_{10}$ oligomers (Fig. 4b). Increasing the $\mathrm{pH}$ of the decavanadate solutions produces the partial depolymerization of $\mathrm{V}_{10}$ to give $\mathrm{V}_{5}, \mathrm{~V}_{4}$, and $\mathrm{V}_{2}$ (Fig. 4c). At low concentrations (1-5 $\mathrm{mM} \mathrm{NaVO}$ ), $\mathrm{V}_{10}$ is the predominant species and $\mathrm{V}_{2}$ is the main metavanadate in these solutions with $\mathrm{pH}$ adjusted back to high values. As $\left[\mathrm{NaVO}_{3}\right]$ increases, $\mathrm{V}_{4}$ becomes the predominant metavanadate, as in the case of Fig. 4c.

Comparison of Fig. $4 \mathrm{a}$ and $\mathrm{b}$ indicates that clear metavanadate solutions contain vanadate monomers, whereas orange decavanadate solutions at $\mathrm{pH} 8.71$ do not. In all of the orange solutions examined, $\mathrm{V}_{10}$ was always observed and V1 was never observed. Figure 5 shows the concentration of $\mathrm{V}_{1}$ species in clear metavanadate solutions and the concentration of $\mathrm{V}_{10}$ in orange decavanadate solutions as a function of the total vanadate concentration, all at $\mathrm{pH} 8.71$. The concentration of $\mathrm{V}_{10}$ linearly scales with total $\left[\mathrm{NaVO}_{3}\right]$. However, the amount of $V_{1}$ present in clear metavanadate solutions seems to reach a saturation level of $6.5 \mathrm{mM}$.

Table I summarizes the chemical shifts, $\delta$, observed for the different oligomers for both decavanadate and metavanadate solutions at $\mathrm{pH}$ 8.71. At a fixed $\mathrm{pH}$ the chemical shift of the different oligomers does not vary with incremental concentrations of $\mathrm{NaVO}_{3} \cdot{ }^{32,42-44}$ Using chemical shift information, it is possible to determine the state of protonation of the oligomers. Within the experimental error of $0.5 \mathrm{ppm}$, the results are in good agreement with Heath et al. and Crans et al. ${ }^{32,42}$ Nevertheless, the chemical shifts are about $3 \mathrm{ppm}$ more negative than commonly tabulated values. The small discrepancies are probably caused by different experimental conditions such as temperature, ionic strength, and/or $\mathrm{pH}^{42,50}$ For the clear solutions, the chemical shift of the monovanadates indicates that monoprotonated and diprotonated $\mathrm{V}_{1}$ are present. Likewise, for both clear and orange solutions, the chemical shift for the divanadate species indicates that $\mathrm{HV}_{2} \mathrm{O}_{7}^{3-}$ and $\mathrm{H}_{2} \mathrm{~V}_{2} \mathrm{O}_{7}^{2-}$ are at equilibrium. As hypothesized by 
Heath et al., the slightly more negative chemical shifts for both $\mathrm{V}_{4}$ and $\mathrm{V}_{5}$ may correspond to an equilibrium reaction between cyclic and linear oligomers. ${ }^{42}$ In addition, for the orange solutions, the position of the three $\mathrm{V}_{10}$ peaks seems to indicate that the decavanadate species at metastable equilibrium are $\mathrm{HV}_{10} \mathrm{O}_{28}^{5-}$ and $\mathrm{H}_{2} \mathrm{~V}_{10} \mathrm{O}_{28}^{3-32}$

Inhibition by metavanadate and decavanadate solutions. - The corrosion-inhibiting effects of orange solutions containing decavanadate but no monovanadate and clear solutions containing metavanadates $\left(\mathrm{V}_{1}-\mathrm{V}_{5}\right)$ but no decavanadate were determined at the fixed $\mathrm{pH}$ of 8.71 . These solutions will be referred to as orange decavanadate and clear metavanadate solutions, respectively, even though the former solutions also contain some metavanadates. Cathodic polarization curves of AA2024-T3 were measured in orange decavanadate and clear metavanadate $\mathrm{pH} 8.71$ solutions containing $0.5 \mathrm{M} \mathrm{NaCl}$ and varying amounts of $\mathrm{NaVO}_{3}$. Figure 6a compares typical cathodic polarization curves for $100 \mathrm{mM} \mathrm{NaVO}$ solutions. A cathodic polarization curve in $0.5 \mathrm{M} \mathrm{NaCl}$ with no vanadates is also shown for reference. In the absence of inhibitor, the ORR is not impeded and a limiting current, $i_{\mathrm{L}}$, of $25-30 \mu \mathrm{A} / \mathrm{cm}^{2}$ is observed. The $i_{L}$ obtained in $\mathrm{Cu}$-containing aluminum alloys is significantly larger than in pure $\mathrm{Al}$ or in $\mathrm{Al}$ alloys not alloyed with $\mathrm{Cu}$. Although not completely understood, it is generally accepted that the presence of $\mathrm{Cu}$ contamination in the passive film on the matrix or on intermetallic particles increases conductivity of the oxide, making the diffusion of oxygen the rate-limiting step. ${ }^{54-56} \mathrm{In}$ pure $\mathrm{Al}$, the alumina layer acts as an electric isolator, causing electron transfer throughout the film to be extremely difficult. The ability to sustain a large cathodic current makes Al-Cualloys very susceptible to localized corrosion. ${ }^{55}$ Therefore, if a corrosion inhibitor in the aggressive electrolyte controls the kinetics of oxygen reduction, a diminished corrosion rate is expected. ${ }^{9,10,13,14,21,52,55,57,58}$

Figure 6a shows that orange decavanadate solutions do not reduce the kinetics of ORR significantly. For a $100 \mathrm{mM}$ decavanadate solution, an average $i_{\mathrm{L}}$ of $8-15 \mu \mathrm{A} / \mathrm{cm}^{2}$ is observed. The effects of $\mathrm{NaVO}_{3}$ concentration are summarized in Fig. 6b. Comparison of the effects of vanadate on ORR kinetics is complicated by the different shapes of the polarization curves, especially at low potentials. The current density values plotted in Fig. $6 \mathrm{~b}$ were obtained by extrapolating the linear regions of the cathodic curves to the high potential of $-800 \mathrm{mV} \mathrm{SCE}$. This is an arbitrary definition and different approaches could have been taken. However, it gives a fair representation of the inhibition efficacy. Higher vanadate concentrations resulted in larger cathodic currents for the orange decavanadate solutions, supporting the concept that decavanadates are poor inhibitors of the ORR. The small amount of inhibition observed in decavanadate solutions is possibly a consequence of the presence of metavanadates such as $\mathrm{V}_{2}$. As the $\mathrm{NaVO}_{3}$ concentration increases, the amounts of $\mathrm{V}_{10}$ and $\mathrm{V}_{4}$ increase accordingly, lowering the $\mathrm{V}_{2} / \mathrm{V}_{4}$ ratio. It is hypothesized that adsorption of $\mathrm{V}_{2}$ is somehow impeded by the presence of $\mathrm{V}_{4}$ and $\mathrm{V}_{10}$, which lowers the inhibition extent by allowing oxygen to adsorb freely on the local cathodes and then reduce.

In contrast to the orange decavanadate solutions, a significant decrease in the rate of oxygen reduction was observed in clear metavanadate solutions. The kinetics of oxygen reduction were reduced by almost 4 orders of magnitude and no diffusion-limiting region was observed (Fig. 6a). In addition, the threshold for hydrogen evolution was shifted toward more negative overpotentials. In further contrast to the orange decavanadate solutions, inhibition performance increased with increasing vanadate concentration (Fig. 6b). Since the orange 
decavanadate solutions contain no $V_{1}$ and the clear metavanadate solutions contain no $\mathrm{V}_{10}$, these results suggest that decavanadates are detrimental or ineffective inhibitors and monovanadates provide the best inhibition. In this regard, the extent of inhibition imparted by monovanadates is similar to that reported for chromates and dichromates in aqueous solutions. ${ }^{21,23,57}$
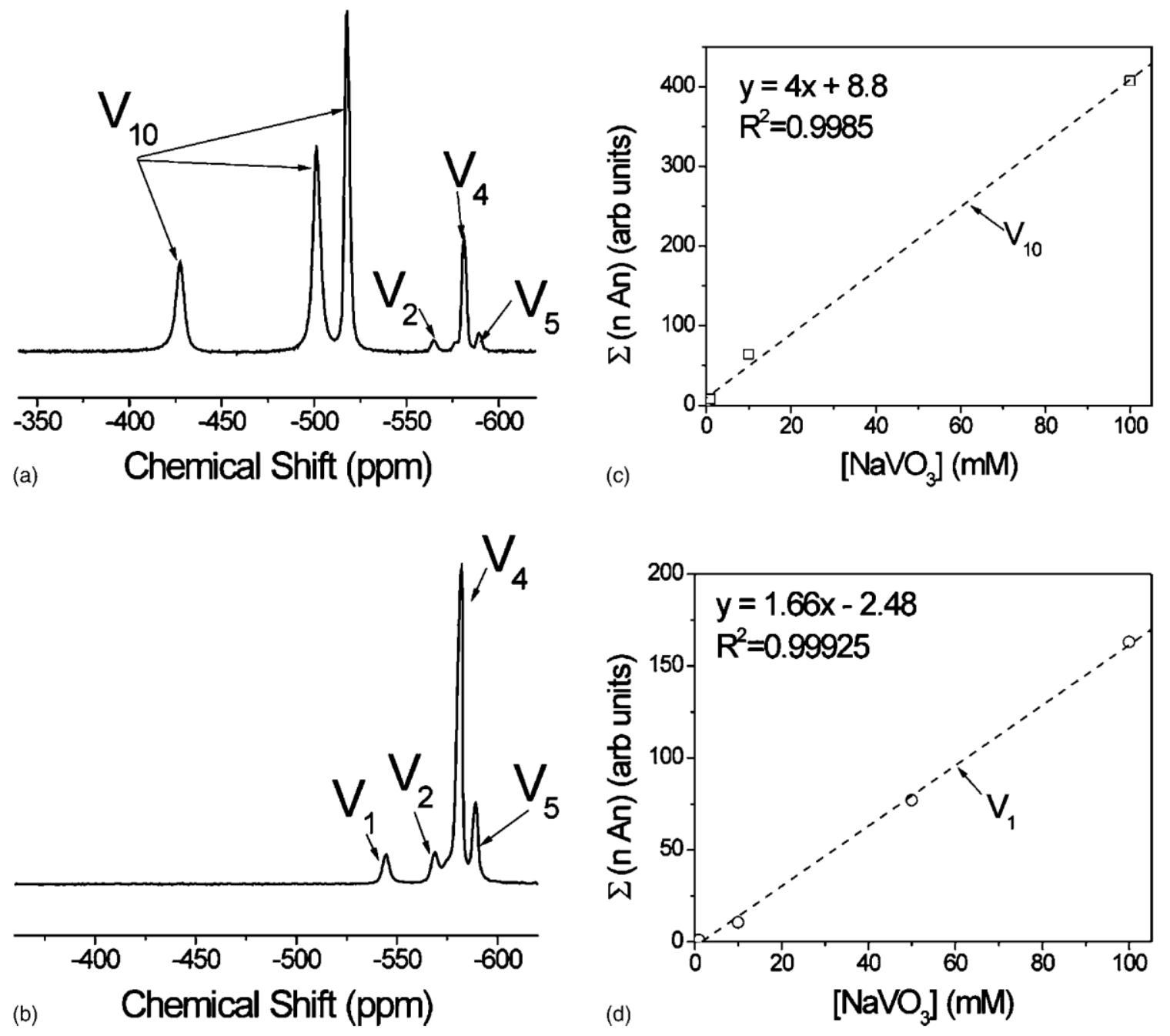

Figure 3. Assignment of ${ }^{51} \mathrm{~V}$ NMR peaks and calibration: (a) typical ${ }^{51} \mathrm{~V}$ NMR spectrum for an orange decavanadate solution, (b) typical ${ }^{51} \mathrm{~V}$ NMR spectrum for a clear metavanadate solution, (c) calibration curve for orange decavanadate solutions, and (d) calibration curve for clear metavanadate solutions. 


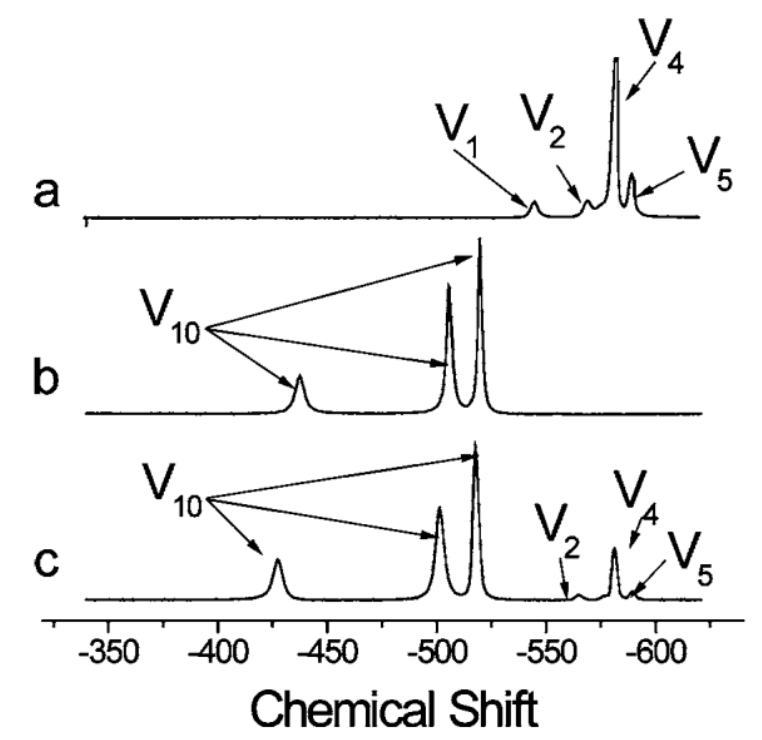

Figure 4. ${ }^{51}$ V NMR spectra of $100 \mathrm{mM}$ vanadate solution in different conditions: (a) as-dissolved $\mathrm{pH}$ 8.71,(b) acidified to $\mathrm{pH} 4$, and (c) acidified and readjusted to $\mathrm{pH} 8.71$
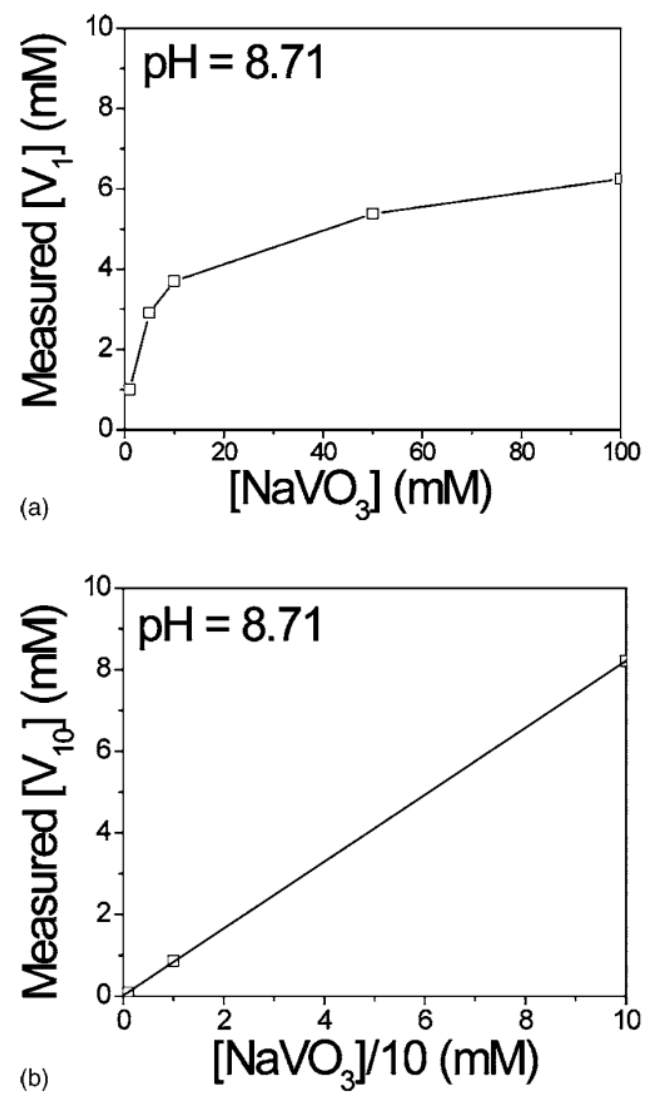

Figure 5. Concentration of $\mathrm{V}_{1}$ and $\mathrm{V}_{10}$ as a function of total $\left[\mathrm{NaVO}_{3}\right]$ : (a) clear metavanadate solutions and (b) orange decavanadate solutions. All at $\mathrm{pH} 8.71$. 
Table I. Chemical shift for the different oligomers present in clear and orange solutions obtained by ${ }^{51} \mathrm{~V}$ NMR.

\begin{tabular}{lcc} 
& Species & Chemical shift $(\mathrm{ppm})$ \\
\hline \multirow{2}{*}{ Clear } & $\mathrm{V}_{1}$ & -545.55 \\
& $\mathrm{~V}_{2}$ & -569.62 \\
& $\mathrm{~V}_{4}$ & -581.13 \\
& $\mathrm{~V}_{5}$ & -589.34 \\
Orange & $\mathrm{V}_{2}$ & -565.17 \\
& $\mathrm{~V}_{4}$ & -581.50 \\
& $\mathrm{~V}_{5}$ & -589.94 \\
& $\mathrm{~V}_{10}$ & -426.84 \\
& & -501.58 \\
& & -517.97
\end{tabular}
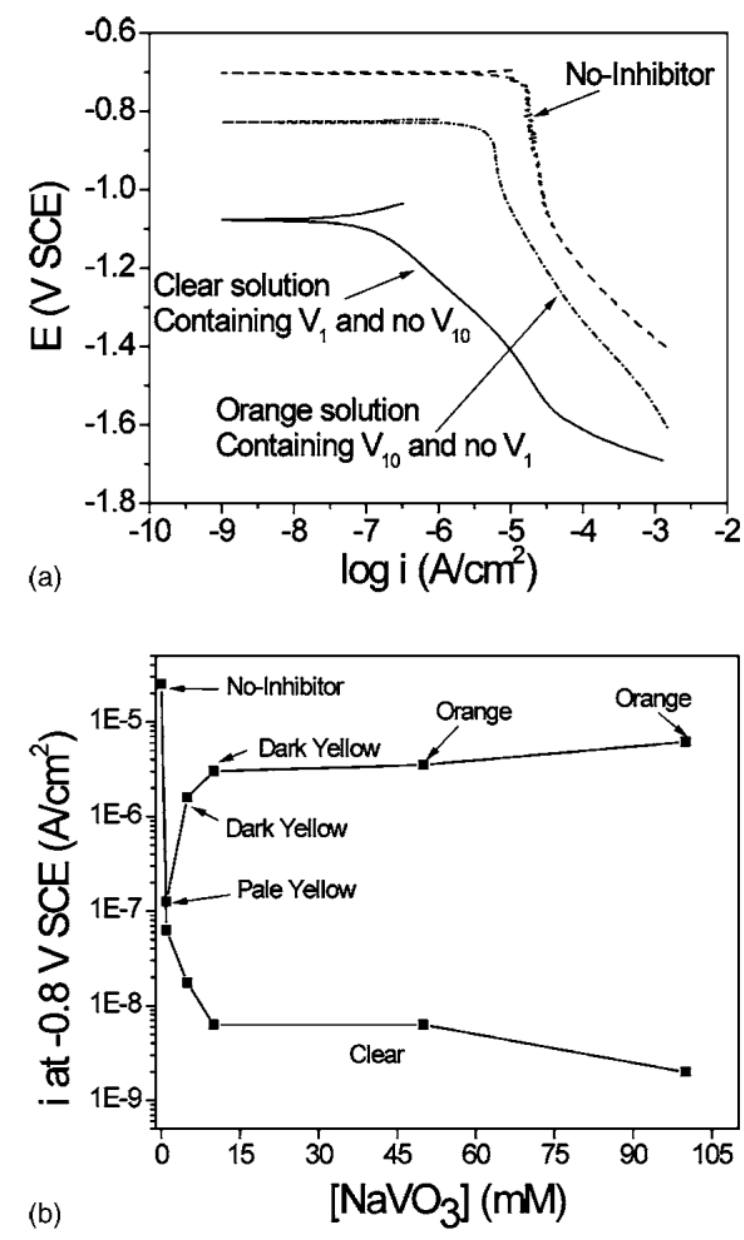

Figure 6. Inhibition of ORR by vanadate solutions. (a) Cathodic polarization curves of AA2024-T3 in 0.5 $\mathrm{M} \mathrm{NaCl}$ with no inhibitor, orange decavanadate, or clear metavanadate. (b) Effects of vanadate concentration on inhibition efficiency measured by calculating the cathodic current at $E=-800 \mathrm{mV}$ SCE.

These data provide no insight on whether the monomers are adsorbed or reduced at the surface. The mechanisms of inhibition by V1 will be discussed in a future communication. However, it is 
important to note that the efficacy of vanadate inhibition seems to reach a limiting value in the same range of $\mathrm{NaVO}_{3}$ concentrations where the $\mathrm{V} 1$ concentration reaches a limiting value (Fig. $5)$.

A comparison of the long-term performance of orange decavanadate and clear metavanadate solutions was carried out by analyzing polarization resistance values, $R_{P}$, extracted by LPT and by optical inspection after OCP exposure. Samples of AA2024-T3 were exposed to aerated $\mathrm{pH} 8.71$ solutions containing $0.5 \mathrm{M} \mathrm{NaCl}$ with or without vanadates as indicated. Typical results are shown in Fig. 7. In the absence of inhibitor, $R_{P}$ varied between 5 and $10 \Omega \mathrm{cm}^{2}$, and samples were severely pitted after the $24 \mathrm{~h}$ experiment. The fluctuation of $R_{P}$ in the solution without inhibitor is probably associated with the pitting corrosion. An orange decavanadate solution containing $6.26 \mathrm{mM} \mathrm{V}_{10}$ (present in a solution that was initially $100 \mathrm{mM} \mathrm{NaVO}$ ) exhibited $R_{P}$ values that fluctuated between 50 and $300 \Omega \mathrm{cm}^{2}$ initially. However, after about $5 \mathrm{~h}$, $R_{P}$ decreased with time to $10-30 \Omega \mathrm{cm}^{2}$. In contrast, in a clear metavanadate solution containing 1 $\mathrm{mM} \mathrm{V} \mathrm{V}_{1}$, significantly higher $R_{P}$ values were observed. Polarization resistance typically varied between 300 and $1100 \Omega \mathrm{cm}^{2}$ and was virtually independent of $\mathrm{NaVO}_{3}$ concentration above 1 $\mathrm{mM}$. The low corrosion rate was sustained during the $24 \mathrm{~h}$ of exposure. Samples exposed at OCP to orange decavanadate solutions containing $\mathrm{NaCl}$ rapidly developed pits that could be ob-

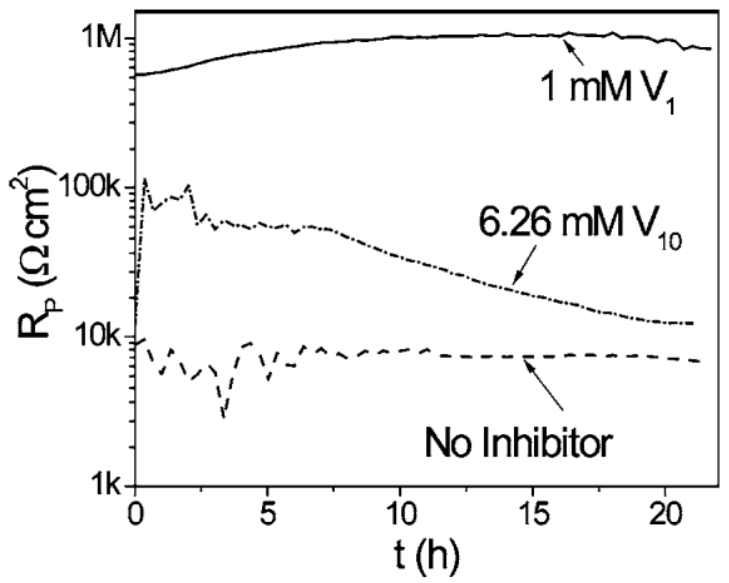

Figure 7. Polarization resistance of AA2024-T3 in $0.5 \mathrm{M} \mathrm{NaCl}$ solutions containing no inhibitor, $1 \mathrm{mM} \mathrm{V}_{1}$ or $6.26 \mathrm{mM} \mathrm{V}_{10}$.

served easily with the unaided eye. Figure 8a is an optical micrograph of an AA2024-T3 after 14 days in an orange decavanadate + chloride solution with initial total vanadate concentration of 10 $\mathrm{mM}$. Very large pits at the surface are evident. In contrast, only small pits were observed after exposure to clear metavanadate + chloride solutions (Fig. 8b). Interestingly, in both cases, pits were always covered by a corrosion product that was enriched in vanadium as shown by EDS (Fig. 8c). The scratches observed in Fig. 8c and d are common for AA2024-T3 polished to $1 \mu \mathrm{m}$ diamond paste. Atomic force microscopy measurements revealed that the scratches are less than $1 \mu \mathrm{m}$ deep. Similar results were obtained for samples only polished to 1200 grit.

Since high-pH orange decavanadate solutions are not at thermodynamic equilibrium, it was of interest to analyze the effects of solution aging on corrosion inhibition performance. A $100 \mathrm{mM}$ orange decavanadate solution adjusted to $\mathrm{pH} 8.71$ was aged for 10 days. Samples were extracted 
for ${ }^{51} \mathrm{~V}$ NMR analysis and electro-chemical characterization after 1, 3, and 10 days. The solution $\mathrm{pH}$ decreased slowly over time; therefore, $\mathrm{pH}$ was readjusted to 8.71 before the experiments.

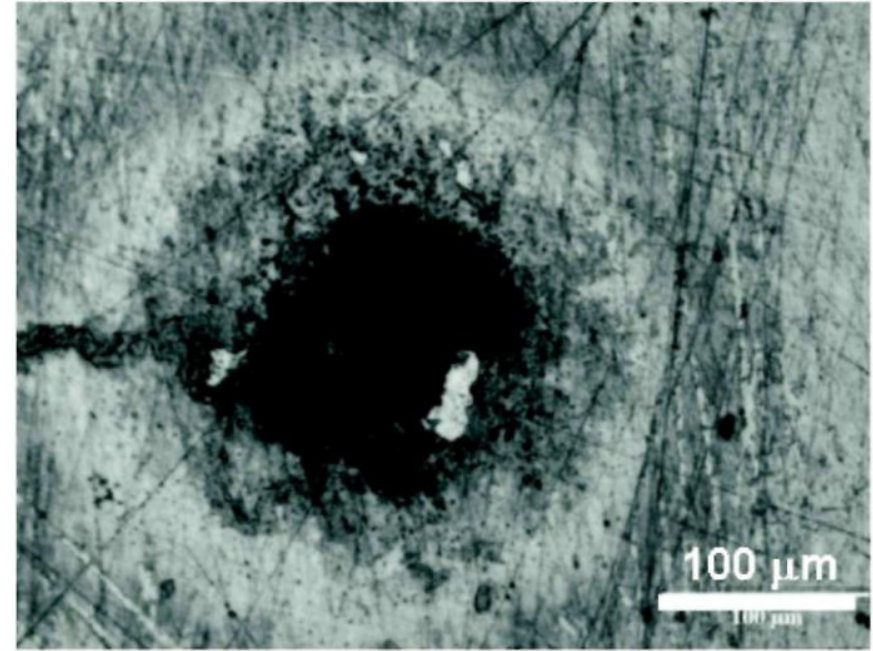

(a)

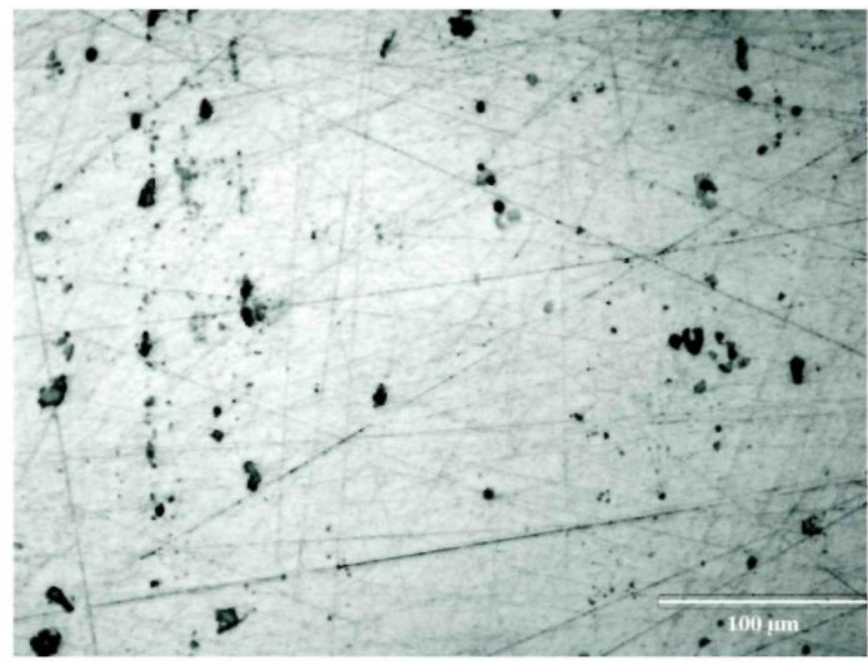

(b)

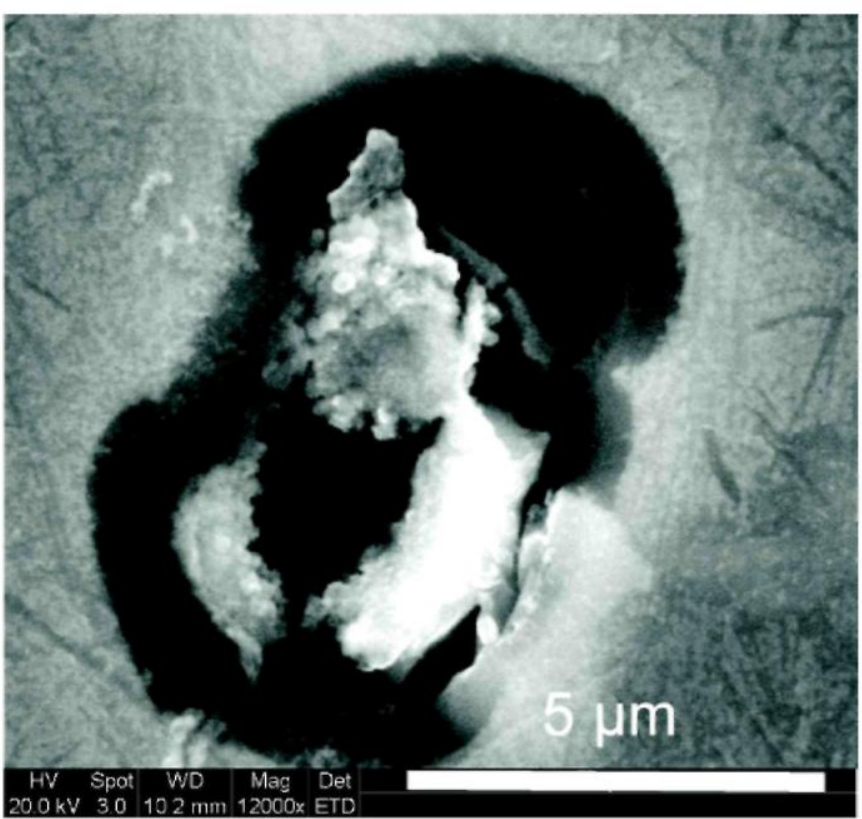

(c)

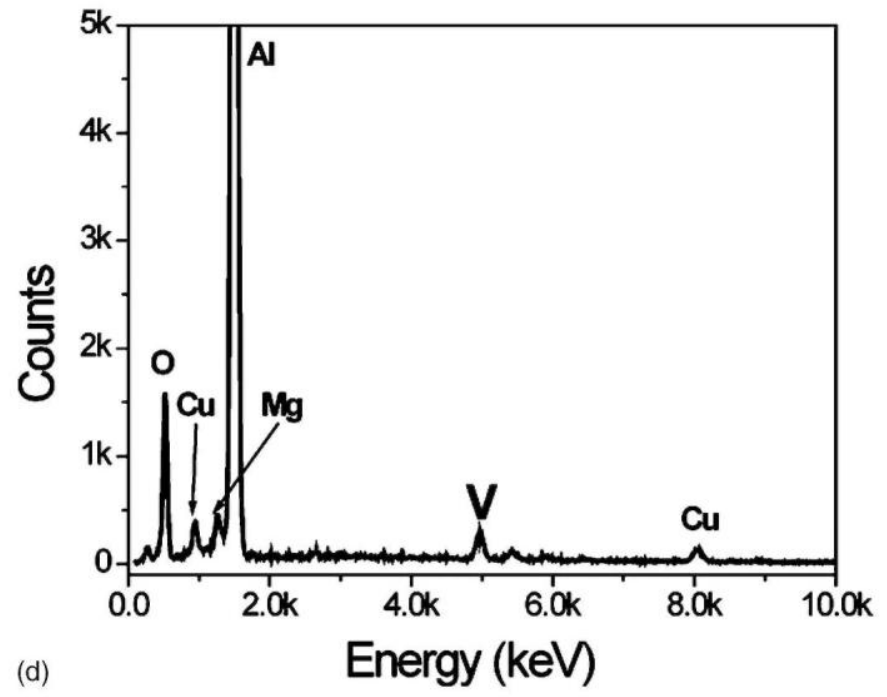

Figure 8. Optical micrographs of AA2024-T3 after 14 days of exposure to aerated $0.5 \mathrm{M} \mathrm{NaCl}$ containing (a) $\mathrm{V}_{10}$ and (b) V1. (c) Secondary electron image of a small pit nucleated after 14 days exposure to $\mathrm{V}_{1}$, and EDS analysis of the corrosion products showing enrichment in vanadium. 

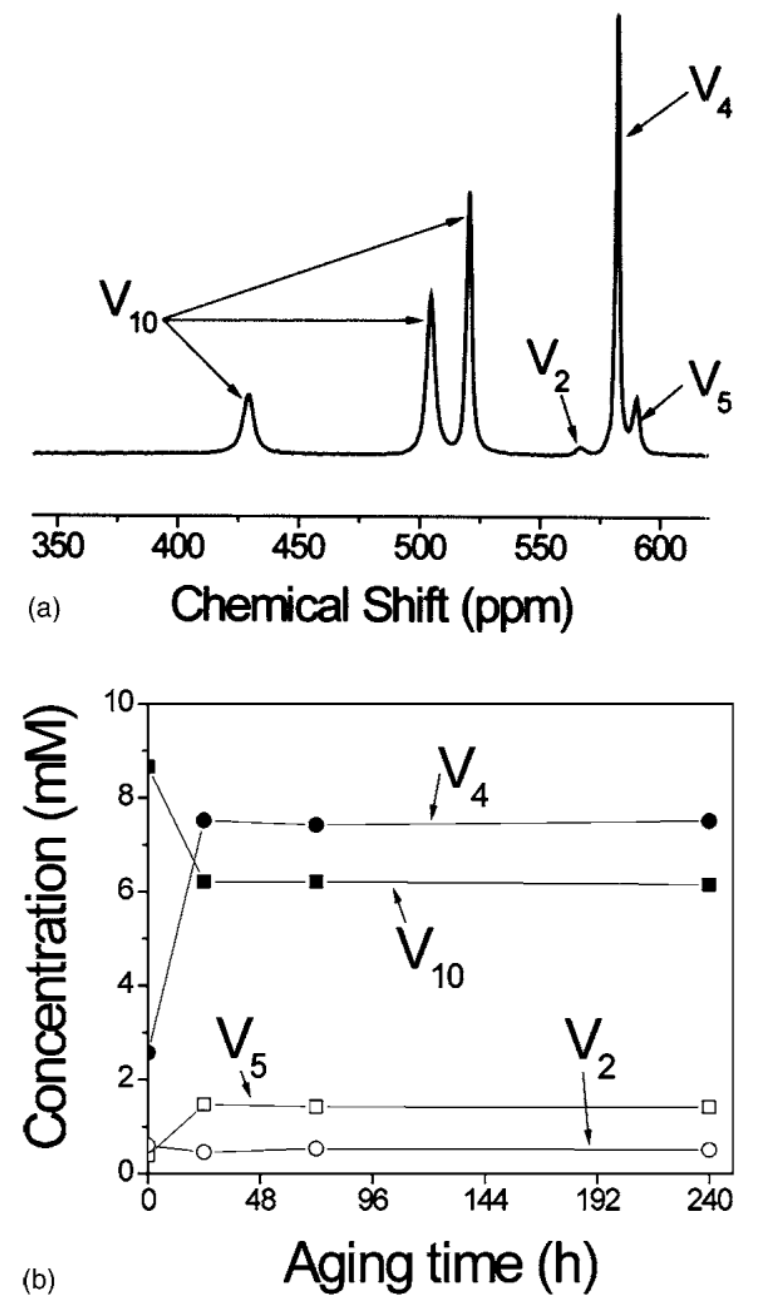

Figure 9. Effect of aging. (a) ${ }^{51} \mathrm{~V}$ NMR spectrum of a $100 \mathrm{mM}$ orange decavanadate solution aged $24 \mathrm{~h}$ and (b) concentration of the different oligomers as a function of aging time.

The ${ }^{51} \mathrm{~V}$ NMR spectrum shows that after $24 \mathrm{~h}$ aging the amount of $\mathrm{V}_{10}$ was reduced and $\mathrm{V}_{4}$ became predominant (Fig. 9a). However, decavanadate was still present and monovanadate did not form during aging, indicating that the depolymerization to form $V_{1}$ is not favored under these conditions. After 3 and 10 days no significant changes in speciation were observed (Fig. 9b). This suggests that the rate of depolymerization is extremely slow. Samples without $\mathrm{pH}$ readjustment were also analyzed for comparison. Except for small changes in $\delta$, no significant differences in speciation were found. Consequently, from a practical standpoint, polymerization of $\mathrm{V}_{10}$ is not completely reversible.

Cathodic polarization curves did not show significant variations with aging time of the orange decavanadate solutions (Fig. 10). A large limiting current associated with a relatively fast rate of ORR was observed. Similarly, the OCP was $300 \mathrm{mV}$ more positive than the OCP in clear metavanadate solutions. It is interesting that polarization curves in metavanadate solutions were very reproducible, but the scatter for the orange decavanadate solutions was large. The polarization plots shown here represent a lower limit for decavanadate solutions to present 


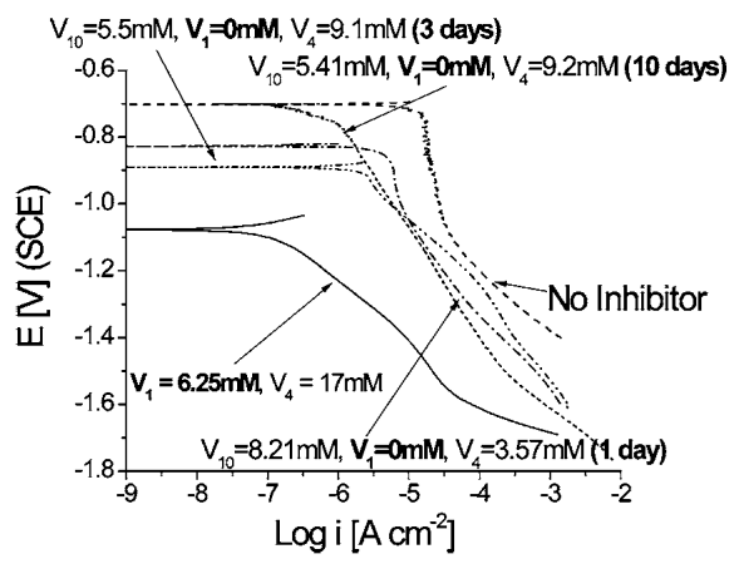

Figure 10. Effects of solution aging on cathodic behavior of AA2024-T3 in orange decavanadate solutions.

conservative results. In many cases currents as large as the limiting current in solutions with no inhibitor added were obtained. Since the main consequence of aging was the rapid formation of $\mathrm{V}_{4}$ species, these findings indicate that inhibition of ORR is not imparted by $\mathrm{V}_{10}$ or by $\mathrm{V}_{4}$. In other words, it seems plausible that the higher molecular weight oligomers do not impart good protection since they cannot lower the rate of $\mathrm{O}_{2}$ reduction.

The effects of incremental $\mathrm{pH}$ on speciation of $10 \mathrm{mM}$ clear metavanadate solutions were also investigated by ${ }^{51} \mathrm{~V}$ NMR. Figure 11a summarizes the variation of the concentration of the different oligomers as a function of $\mathrm{pH}$. As $\mathrm{pH}$ increased, $\mathrm{V}_{1}$ rapidly became predominant and $\mathrm{V}_{5}$ and $\mathrm{V}_{4}$ peaks diminished. Above $\mathrm{pH} 9$ only signals from $\mathrm{V}_{1}$ and $\mathrm{V}_{2}$ were obtained. Chemical shift plotted in Fig. 11b. In good agreement with Heath et al. and Larson, ${ }^{42,44}$ the equilibrium for both $\mathrm{V}_{1}$ and $\mathrm{V}_{2}$ shifted toward the deprotonated form at $\mathrm{pH}>9$. Chemical shift of the higher molecular weight oligomers is virtually independent of $\mathrm{pH} .{ }^{32,42,44}$

Taking into account these findings, it is possible to analyze the effects of $\mathrm{V}_{1}$ concentration, protonation state, and $\mathrm{pH}$ on inhibition. Cathodic polarization experiments in 0.5 $\mathrm{M} \mathrm{NaCl}+10 \mathrm{mM} \mathrm{NaVO}$ with different $\mathrm{pH}$ were carried out and compared with solutions containing no inhibitor at the same pHs. The exact concentration of $V_{1}$ and $V_{2}$ can be extracted from the ${ }^{51} \mathrm{~V}$ NMR data (Fig. 11a).

The polarization curves in the solutions with no inhibitor were identical except for a change in the OCP. All polarization curves in the metavanadate-containing solutions exhibited much lower ORR rates, and there was no clear influence of $\mathrm{pH}$ (and thus $\mathrm{V}_{1}$ concentration) (Fig. 12). This suggests that above a critical concentration, most of the local cathodes are blocked by $\mathrm{V}_{1}$ (or a combination of $\mathrm{V}_{1}$ and $\mathrm{V}_{2}$ ), which greatly reduces the rate of oxygen reduction.

These findings should directly impact the development of new coating systems based on vanadates. To date, most of the work with vanadium compounds was focused on hosting decavanadates in hydrotalcite pigments or in conversion coatings. ${ }^{14,26,30}$ Since monovanadate appears to be the strongest corrosion inhibitor of the system, any coating scheme based on vanadium should release $V_{1}$. The electrolyte developed in atmospheric exposure of aircrafts is thought to be neutral to basic, ${ }^{59}$ which would impede the formation of decavanadate. Special care should also be taken during coating formulation. Since $\mathrm{pHs}<3$ triggers decavanadate formation, the $\mathrm{pH}$ of the coating bath has to remain above that critical level. The main problem of $\mathrm{NaVO}_{3}$ as pigment is its relatively large solubility, which would end up producing blistering after water uptake. However, Smith et al. ${ }^{28,60}$ and Nazarov et al ${ }^{61}$ produced a variety of vanadate pigments 
with a lower solubility than $\mathrm{NaVO}_{3}$, by simply reacting $\mathrm{NaVO}_{3}$ with different metallic chlorides such as $\mathrm{MgCl}_{2}$ and $\mathrm{SrCl}_{2}$. This suggests that it could be possible to have control over the release kinetics.

In addition to the effects of vanadates on the ORR, the effects of both clear metavanadate and orange decavanadate solutions on the anodic reaction were studied in detail and are the topic of a future communication. However, the effects of clear metavanadate solution on the anodic reaction were significantly smaller than the large reduction in the rate of the ORR.

Finally, it is unclear what would happen inside an acidic crevice. However, the absence of crevice attack under masked regions during long-term exposure seems to indicate that the blockage of the local cathodes by monovanadates diminishes any possible anodic dissolution, including crevice corrosion. Nevertheless, a more detailed investigation is still required.
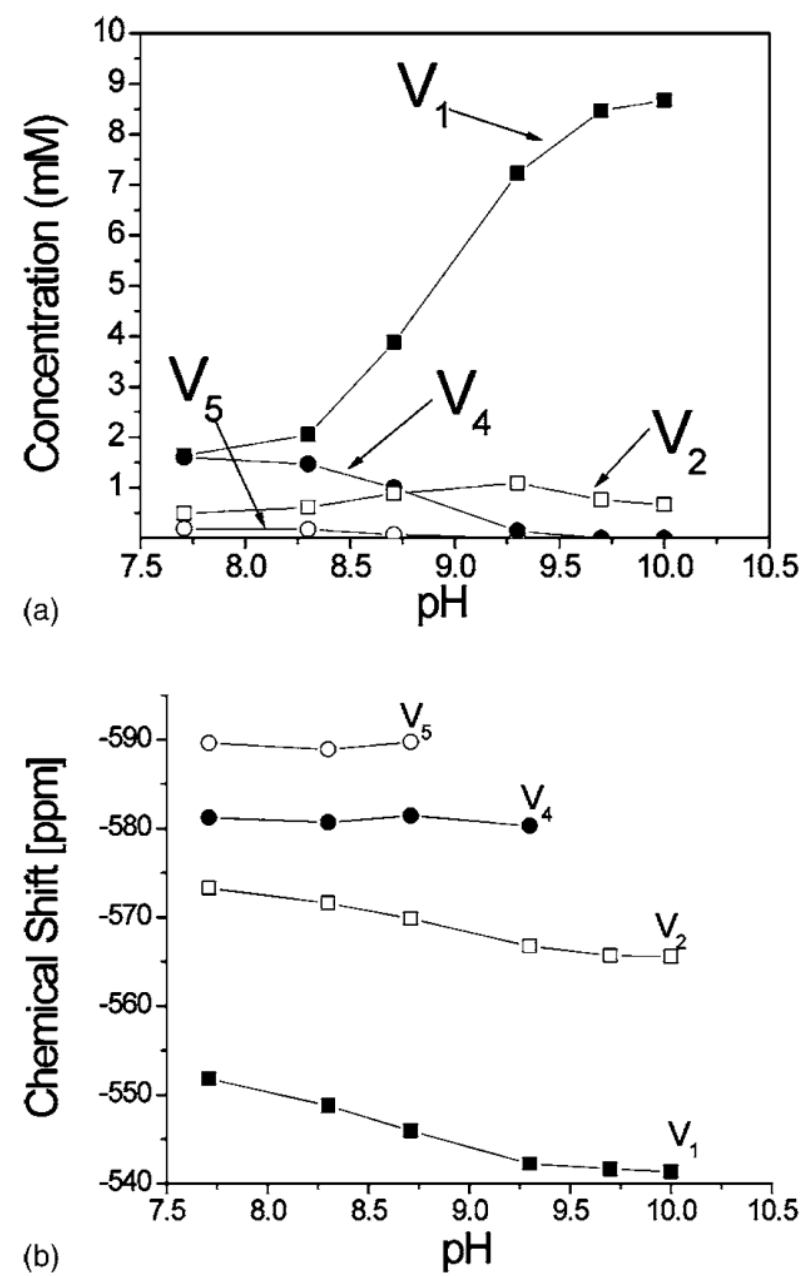

Figure 11. Effect of $\mathrm{pH}$. (a) Concentration of the oligomers present in $10 \mathrm{mM}$ metavanadate solutions as a function of $\mathrm{pH}$ and (b) chemical shift as a function of $\mathrm{pH}$. Above $\mathrm{pH} 9$ signals only from $\mathrm{V}_{1}$ and $\mathrm{V}_{2}$ are observed. 


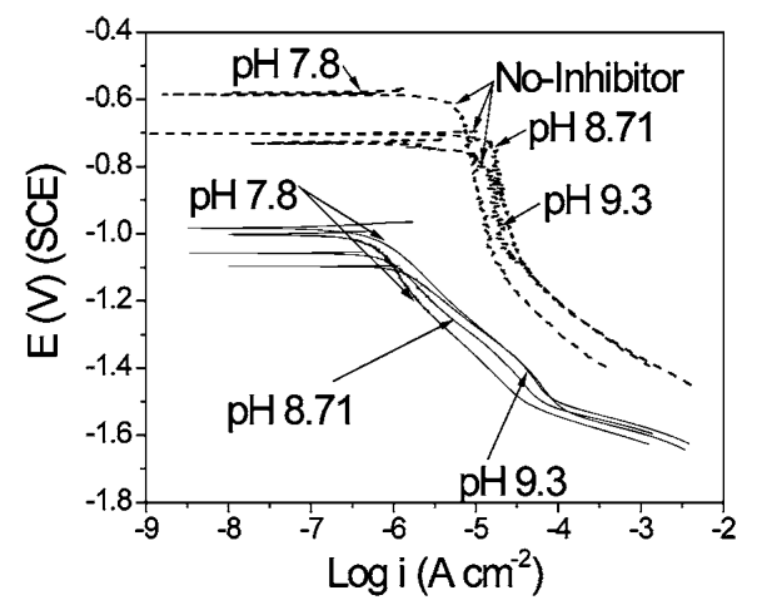

Figure 12. Cathodic polarization curves of AA2024-T3 exposed to $0.5 \mathrm{M} \mathrm{NaCl}$ at high $\mathrm{pH}$ with no inhibitor or clear metavanadate.

\section{Conclusions}

Speciation of vanadate solutions with varying concentrations and $\mathrm{pH}$ was studied by ${ }^{51} \mathrm{~V}$ NMR spectroscopy and the effects of corrosion inhibition for AA2024-T3 were investigated. The following conclusions can be obtained:

1. Decavanadate only formed when metavanadate was added to solutions of $\mathrm{pH} 3$ or less. The final $\mathrm{pH}$ after vanadate addition was independent of the initial $\mathrm{pH}$ for initial $\mathrm{pH}$ of 3 or greater. Therefore, it is impossible to change the $\mathrm{pH}$ of a metavanadate solution without forming decavanadates.

2. Acidification of clear metavanadate solutions to $\mathrm{pH} 4$ or lower polymerized all the oligomers to form $\mathrm{V}_{10}$. Readjusting the $\mathrm{pH}$ to 8.71 produced a partial depolymerization of $\mathrm{V}_{10}$ to form $\mathrm{V}_{2}, \mathrm{~V}_{4}$, and $\mathrm{V}_{5}$. Orange solutions always contained decavanadates and never contained monovanadates.

3. Orange decavanadate solutions containing $0.5 \mathrm{M} \mathrm{NaCl}$ exhibited no significant inhibition of the ORR and increasing decavanadate concentration was detrimental. Aging of the metastable decavanadate solutions for up to 10 days did not improve protection.

4. Clear metavanadate solutions containing monovanadate exhibited strong inhibition of the ORR, to a level similar to chromate. At a fixed $\mathrm{pH}$, increased $\mathrm{NaVO}_{3}$ concentration in clear metavanadate solutions increased inhibition efficiency.

5. Since the orange decavanadate solutions contain no $\mathrm{V}_{1}$ and the clear metavanadate solutions contain no $\mathrm{V}_{10}$, these results suggest that decavanadates are detrimental or ineffective inhibitors and monovanadates provide the best inhibition.

6. As the $\mathrm{pH}$ of clear metavanadate solutions increases, $\mathrm{V}_{1}$ and $\mathrm{V}_{2}$ become the predominant species, but improvement in inhibition was not found.

7. A coating system based on vanadates should be able to release monovandates. The formation of decavanadates during coating formulation should be avoided.

\section{Acknowledgments}

This work was partially funded by AFOSR under award F 49620-02-0321, Major J. Gresham, Ph.D., 
contract monitor.

The Ohio State University assisted in meeting the publication costs of this article.

\section{References}

1. J. R. Davis, ASM Specialty Handbook: Aluminum and Aluminum Alloys, Chap. 2, p. 31, ASM International, Materials Park, OH (1993).

2. C. Kammer, Aluminum Handbook, Vol. 1, 1st ed., Chap. 4, p. 125, Aluminum-Verlag, Düsseldorf, 1999).

3. C. Blanc, B. Lavelle, and G. Mankowski, Corros. Sci., 39, 495 (1997).

4. R. G. Buchheit, R. P. Grant, P. F. Hlava, B. McKenzie, and G. L. Zender, J. Electrochem. Soc., 144, 2621 (1997).

5. G. S. Chen, M. Gao, and R. P. Wei, Corrosion (Houston), 52, 8 (1996).

6. W. Zhang and G. S. Frankel, Electrochim. Acta, 48, 1193 (2003).

7. P. Campestrini, H. Terryn, J. Vereecken, and J. H. W. D. Wit, J. Electrochem. Soc., 151, B370 (2004).

8. P. L. Hagans and C. M. Haas, ASM Handbook, Vol. 5, Surface Engineering, 10th ed., F. Reidenbach, Editor, p. 104, ASM International, Metals Park, OH (1994).

9. M. Kendig and R. G. Buchheit, Corrosion (Houston), 59, 379 (2003).

10. M. Kendig and C. Yan, J. Electrochem. Soc., 151, B679 (2004).

11. M. Koudelkova, J. Augustynski, and H. Berthou, J. Electrochem. Soc., 124, 1165 (1977).

12. P. G. Sheasby and R. Pinner, The Surface Treatment and Finishing of Aluminum and its Alloys, Vol. 1, Chap. 5, p. 231, ASM International, Materials Park, OH (2001).

13. G. S. Frankel and R. L. McCreery, Interface (USA) 2001, 34.

14. R. G. Buchheit, in Corrosion Science: A Retrospective and Current Status in Honor of Robert P. Frankenthal, G. S.Frankel, J. R. Scully, H. S. Isaacs, and J. D. Sinclair, Editors, PV 2002-13, p. 430, The Electrochemical Society Proceedings Series, Pennington, NJ (2002).

15. P. Campestrini, G. Goeminne, H. Terryn, and J. Vereecken, J. Electrochem. Soc., 151, B70 (2004).

16. J. S. Crompton, P. R. Andrews, and E. M. Alpine, Surf. Interface Anal., 13, 160 (1988).

17. C. S. Jeffcoate, H. S. Isaacs, A. J. Aldykiewicz, and M. P. Ryan, J. Electrochem. Soc., 147, 540 (2000).

18. B. L. Hurley and R. L. McCreery, J. Electrochem. Soc., 150, B367 (2003).

19. G. P. Halada and C. R. Clayton, J. Electrochem. Soc., 138, 2921 (1991).

20. J. Wan, G. E. Thompson, K. Lu, and C. J. E. Smith, Physica B, 208 \& 209, 511 (1995).

21. M. Kendig, S. Jeanjaquet, R. Addison, and J. Waldrop, Surf. Coat. Technol., 140, 58 (2001).

22. J. H. Osborne, Prog. Org. Coat., 41, 280 (2001).

23. J. Zhao, L. Xia, A. Sehgal, D. Lu, R. L. McCreery, and G. S. Frankel, Surf. Coat. Technol., 140, 51 (2001);

24. L. Xia, E. Akiyama, G. S. Frankel, and R. L. McCreery, J. Electrochem. Soc., 147, 2556 (2000).

25. USAF Blue Ribbon Advisory Panel Report on Aircraft Coatings, Materials Directorate, Wright Laboratory (1995).

26. H. Guan and R. G. Buchheit, Corrosion (Houston), 60, 284 (2004).

27. M. Trypuc and G. Lyjak, Polish J. App. Chem., XLI (z3), 187 (1997).

28. C. J. E. Smith, M. A. H. Hewins, P. L. Lane, K. R. Baldwin, and M. C. Gibson, in Proceedings of Eurocorr 98, Utrecht, The Netherlands, Paper N 5 (1998).

29. R. L. Cook and S. R. Taylor, Corrosion (Houston), 56, 321 (2000).

30. R. G. Buchheit, H. Guan, S. Mahajanam, and F Wong, Prog. Org. Coat., 47, 174 (2003).

31. B. D. Chambers, S. R. Taylor, and M. W. Kendig, Corrosion (Houston), 61, 480 (2005).

32. D. C. Crans and A. S. Tracey, ACS Symp. Ser., 711, 2 (1998).

33. L. Petterson and K. Elvigson, ACS Symp. Ser., 711, 30 (1998).

34. L. Petersson, Mol. Eng., 3, 29 (1993).

35. J. J. Cruywagen, Adv. Inorg. Chem., 49, 127 (2000).

36. A. F Holleman and E. Wiberg, Inorganic Chemistry, Academic Press, New York (2001).

37. L. Bouhedja, N. Steunou, J. Maquet, and J. Livage, J. Solid State Chem., 162, 315 (2001).

38. J. Livage, Chem. Mater, 3, 578 (1991).

39. M. Aureliano and R. M. C. Gandara, J. Inorg. Biochem., 99, 979 (2005). 
40. D. Rehder, Coord. Chem. Rev., 182, 297 (1999).

41. O. W. Howarth and R. E. Richards, J. Chem. Soc., 2, 864 (1965).

42. E. Heath and O. W. Howarth, J. Chem. Soc. Dalton Trans., 2, 1105 (1981).

43. A. S. Tracey, J. S. Jaswal, and S. J. Angus-Dunne, Inorg. Chem., 34, 5680 (1995).

44. J. W Larson, J. Chem. Eng. Data, 40, 1276 (1995).

45. A. S. Tracey, Coord. Chem. Rev., 237, 113 (2003).

46. A. S. Tracey, M. J. Gresser, and K. M. Parkinson, Inorg. Chem., 26, 629 (1987).

47. A. S. Tracey and C. H. Leon-Lai, Inorg. Chem., 30, 3200 (1991).

48. M. T. Pope and B. W. Dale, Q. Rev., Chem. Soc., 22, 527 (1968).

49. S. E. O'donnell and M. T. Pope, J. Chem. Soc. Dalton Trans., 4, 2290 (1976).

50. J. B. Lambert and E. P. Mazzola, Nuclear Magnetic Resonance Spectroscopy: An Introduction to Principles, Applications, and Experimental Methods, Chap. 1, Pearson Prentice Hall, Englewood Cliffs, NJ (1999).

51. G. A. Pozarnsky and A. V. McCormick, Chem. Mater, 6, 380 (1994).

52. G. O. Ilevbare and J. R. Scully, J. Electrochem. Soc., 148, B196 (2001).

53. M. B. Vukmirovic, N. Dimitrov, and K. Sieradzki, J. Electrochem. Soc., 149, B428 (2002).

54. M. B. Vukmirovic, N. Vasiljevic, N. Dimitrov, and K. Sieradzki, J. Electrochem. Soc., 150, B10 (2003).

55. G. O. Ilevbare and J. R. Scully, Corrosion (Houston), 57, 134 (2001).

56. D. Chidambaram, C. R. Clayton, and G. P. Halada, J. Electrochem. Soc., 151, B151 (2004).

57. W. J. Clark, J. D. Ramsey, R. L. McCreery, and G. S. Frankel, J. Electrochem. Soc., 149, B179 (2002).

58. M. Kendig, M. Hon, and L. Warren, Prog. Org. Coat., 47, 183 (2003).

59. M. E. Inman, R. G. Kelly, S. A. Willard, and R. S. Plascik, in Proceedings of the ASIP Conference, Atlanta, GA, U.S. Air Force (Nov 1996).

60. C. J. E. Smith, ATB Metalurgie, 37, 266 (1997).

61. A. Nazarov, D. Thierry, T. Prosek, and N. L. Bozec, J. Electrochem. Soc., 152, B220 (2005). 